\title{
Current and Future Outlook on Disease Modification and Defining Low Disease Activity in Systemic Sclerosis
}

\author{
Vivek Nagaraja, ${ }^{1}$ (D) Marco Matucci-Cerinic, ${ }^{2}$ Daniel E. Furst, ${ }^{3}$ Masataka Kuwana, ${ }^{4}$ (D) Yannick Allanore, ${ }^{5}$ \\ Christopher P. Denton, ${ }^{6}$ Ganesh Raghu, ${ }^{7}$ Vallerie Mclaughlin, ${ }^{1}$ Panduranga S. Rao, ${ }^{1}$ James R. Seibold, ${ }^{8}$ \\ John D. Pauling, ${ }^{9}$ (i) Michael L. Whitfield, ${ }^{10}$ and Dinesh Khanna ${ }^{1}$ (D)
}

Systemic sclerosis (SSc) is an autoimmune rheumatic disease with heterogeneous clinical manifestations and a variable course in which the severity of the pathology dictates the disease prognosis and course. Among autoimmune rheumatic diseases, SSc has the highest mortality rate among all rheumatic diseases, though there are exciting new therapeutic targets that appear to halt the progression of SSc manifestations such as skin or lung fibrosis. In selected patients, high-intensity regimens with autologous stem cell transplantation can favorably modify the course. In what was once thought to be an untreatable disease, targeted therapies have now changed the outlook of SSc to a treatable disorder. Herein, we discuss the targeted therapies modifying the outlook on selected organ involvement and creating opportunities for future treatment. We also present a framework for defining low disease activity in SSc.

\section{INTRODUCTION}

Systemic sclerosis (SSc) is a rare disease characterized by vasculopathy and fibrosis in the skin and internal organs (1). The proposed pathophysiology is a triad of vascular damage with endothelial dysfunction, dysregulation of innate and adaptive immunity, and widespread fibrosis in multiple organs $(2,3)$.

Drs. Furst and Raghu's work was supported by the NIH. Dr. Khanna's work was supported by the National Institute of Arthritis and Musculoskeletal and Skin Diseases, NIH (grants K24-AR-063120 and R01-AR-07047) and the National Institute of Allergy and Infectious Disease, NIH.

${ }^{1}$ Vivek Nagaraja, MD, Vallerie Mclaughlin, MD, Panduranga S. Rao, MD, Dinesh Khanna, MD, MSc: University of Michigan, Ann Arbor; ${ }^{2}$ MarcoMatucci Cerinic, MD, PhD: University of Florence, Florence, Italy; ${ }^{3}$ Daniel E. Furst, MD: University of California, Los Angeles, University of Washington, Seattle, and University of Florence, Florence, Italy; ${ }^{4}$ Masataka Kuwana, MD, PhD: Nippon Medical School, Tokyo, Japan; ${ }^{5}$ Yannick Allanore, MD, PhD: Paris Descartes University, INSERM U116, Université Sorbonne Paris Cité, and Cochin Hospital, Paris, France; ${ }^{6}$ Christopher P. Denton, MD: University College London and Royal Free Hospital, London, UK; ${ }^{7}$ Ganesh Raghu, MD: University of Washington, Seattle; ${ }^{8}$ James R. Seibold, MD: Scleroderma Research Consultants, LLC, Aiken, South Carolina; ${ }^{9}$ John D. Pauling, BMedSci, BMBS, PhD, FRCP: Royal National Hospital for Rheumatic Diseases, Royal United Hospitals, Bath, UK; ${ }^{10}$ Michael L. Whitfield, PhD: Geisel School of Medicine at Dartmouth, Hanover, New Hampshire.

Dr. Nagaraja has received honoraria from Eicos Sciences. Dr. Cerinic has received consulting fees from Bristol-Myers Squibb, Pfizer, ChemomAb, Actelion, Janssen, and Eli Lilly (less than $\$ 10,000$ each). Dr. Furst has received consulting fees from Amgen, Bristol-Myers Squibb, Corbus, Galapagos, Novartis, Pfizer, Roche/Genentech, Talaris, CSL Behring, and Boehringer Ingelheim (less than $\$ 10,000$ each) and research support from Bristol-Myers Squibb, Corbus, Galapagos, GlaxoSmithKline, Pfizer, Sanofi, Talaris, and CSL Behring. Dr. Kuwana has received consulting fees from Actelion, Roche/Chugai, Bayer, Boehringer Ingelheim, Corbus, and GlaxoSmithKline (less than $\$ 10,000$ each) and speaking fees from Roche/Chugai and Actelion (less than $\$ 10,000$ each). Dr. Allanore has received consulting fees from Actelion, Bayer, Bristol-Myers
The mortality rate in SSc is higher than in any other rheumatic disease $(4,5)$.

In contrast to rheumatoid arthritis (RA), the concept and use of disease-modifying therapies that attenuate or reverse pathology and clinical impact are not currently applied to SSc. The notion of disease modification in SSc has now advanced to reality based on data from recent clinical trials. Autologous hematopo-

Squibb, Curzion, Boehringer Ingelheim, Inventiva, Roche, and Sanofi (less than $\$ 10,000$ each). Dr. Denton has received consulting fees, speaking fees, and/or honoraria from Roche/Genentech, Actelion, GlaxoSmithKline, Sanofi/Aventis, Acceleron, Inventiva, CSL Behring, Boehringer Ingelheim, and Bayer (less than $\$ 10,000$ each). Dr. Raghu has received consulting fees from Avalyn, Acceleron, Biogen, Blade Therapeutics, Bridge Biotherapeutics, Bristol-Meyers Squibb, Bellerophon, FibroGen, Gilead Sciences, IQVIA, Promedior, Nitto, Respivant, Roche/Genentech, Sanofi/Aventis, Veracyte, Zambon, and Boehringer Ingelheim (less than $\$ 10,000$ each). Dr. Mclaughlin has received consulting fees from Actelion, Acceleron, Arena, Bayer, Caremark, Gilead, SoniVie, and United Therapeutics (less than $\$ 10,000$ each). Dr. Seibold has received consulting fees from Atlantic, Blade, Eicos, Eiger, Indalo, Mitsubishi, Bayer, Boehringer Ingelheim, Camurus, Corbus, EMD Serono, DRG, and Guidepoint (less than $\$ 10,000$ each) and owns stock or stock options in BriaCell and Pacific Therapeutics. Dr. Pauling has received consulting fees from Actelion, Boehringer Ingelheim, and Sojournix (less than $\$ 10,000$ each) and research support from Actelion. Dr. Whitfield has received consulting fees from Bristol-Myers Squibb and Celdara Medical (less than $\$ 10,000$ each). Dr. Khanna has received consulting fees from Actelion, AstraZeneca, Bayer, Bristol-Myers Squibb, Boehringer Ingelheim, ChemomAb, Corbus, CSL Behring, Cytori, GlaxoSmithKline, Horizon, Pfizer, Regeneron, Roche/Genentech, Sanofi/Aventis, and UCB Pharma (less than $\$ 10,000$ each) and owns stock or stock options in Eicos Sciences. No other disclosures relevant to this article were reported.

Address correspondence to Dinesh Khanna, MD, MSc, University of Michigan, Division of Rheumatology, Department of Internal Medicine, Suite 7C27, 300 North Ingalls Street, SPC 5422, Ann Arbor, MI 48109. E-mail: khannad@med.umich.edu.

Submitted for publication April 12, 2019; accepted in revised form February 27, 2020. 
ietic stem cell transplantation (HSCT) trials in diffuse cutaneous SSc (dcSSc) have demonstrated survival benefit, including meaningful improvements in skin, lung fibrosis, and health-related quality of life (HRQoL) (6-9).

In this report, we discuss specific treatments that have modified the course of organ-specific manifestations in SSc and have started the conversation on defining low disease activity in SSc.

\section{What is disease-modifying therapy?}

We borrow the concept of "disease-modifying therapy" from the use of disease-modifying antirheumatic drugs (DMARDs) and biologic response modifiers in RA. In the past 3 decades, RA treatment has evolved from symptom management to the implementation of DMARDs and/or biologic response modifiers. The early institution of DMARDs or biologic response modifiers in RA induces clinical remission, reduces the frequency of relapse, abrogates joint damage, preserves physical function, improves HRQoL, and prevents long-term disability (10). Similarly, we can conceptualize disease-modifying therapy in SSc as therapies or medication regimens that positively impact the disease course by stabilizing and potentially improving organ function. This, in turn, improves HRQoL and reduces morbidity and mortality (11).

\section{Natural history of the disease}

Understanding the natural history of the SSc disease process is vital to the concept of disease-modifying therapy in the context of timing and patient selection. Early clinical features include Raynaud's phenomenon (RP) and gastroesophageal reflux disease (12). Skin fibrosis is a pathologic hallmark of the disease and is frequently preceded by puffy and swollen fingers. Patients with puffy fingers, definite RP, typical nailfold capillary changes, and the presence of SSc-specific antibodies can be considered to have very-earlydiagnosed SSc $(13,14)$. Thereafter, patients may progress to 1 of 3 clinical disease subsets based on the extent of skin involvement.

Patients with skin involvement restricted to the limbs distal to the elbows or knees, with or without face involvement, are classified as having limited cutaneous SSc (IcSSc). Patients with distal as well as proximal involvement (including the torso) are classified as having dcSSc. A small subset of patients without skin involvement but who have scleroderma-specific antibodies and internal organ involvement are considered to have SSc without scleroderma (15-17). This differentiation is important as dcSSc is associated with higher morbidity and mortality, mainly due to more severe and/or progressive internal organ involvement (18). However, this differentiation of the clinical phenotypes is an oversimplification of the disease process.

The biology of SSc is complex, heterogeneous, and dynamic, with sequentially overlapping features of inflammation, autoimmunity, tissue injury, and fibrosis. Skin thickness is generally progressive within the first 3 years after the start of RP in dcSSc, but there is individual variability $(15,16)$. The extent and severity of skin involvement in dcSSc generally level off by years 4 and 5, and then clinically appear to improve both via de-remodeling and atrophy (19). Only a minority of patients have a new emergence of progressive cutaneous involvement beyond 5 years after disease onset. There is an increased risk for the development of internal organ involvement during the progressive skin phase. For example, in dcSSc, most internal organ involvement (lung, renal, cardiac, and gastrointestinal) occurs in the first 3-5 years after disease onset (Figure 1) (16). In the early phase of dcSSc, internal organ involvement-although clinically silent-may evolve at the same time as progressive skin disease. There are, however, exceptions. For example, pulmonary arterial hypertension $(\mathrm{PAH})$ is generally a late complication that is more common in IcSSc (20). Lung fibrosis can also develop separately from or in conjunction with pulmonary hypertension. Fibrosis can advance in a self-perpetuating manner and may not be driven solely by an immune-mediated process (21).

We believe SSc can be conceptualized as a family of similar diseases - an idea supported by the identification of molecular subsets by whole-genome gene expression profiling, with distinct clinical and serologic features and recognized phases within some subtypes (22). The delayed emergence of new organ involvement and gradual progression of the disease provide clinicians with a realistic opportunity to impede disease progression and change disease course.

\section{Why is disease-modifying therapy a challenge in SSc?}

Many challenges exist in demonstrating disease-modifying effects in SSc patients. First, the disease is heterogeneous with different patterns of evolution among the clinical subsets, as previously outlined (5,23-25). Patients usually present with predominantly vasculopathic complications (such as RP, digital

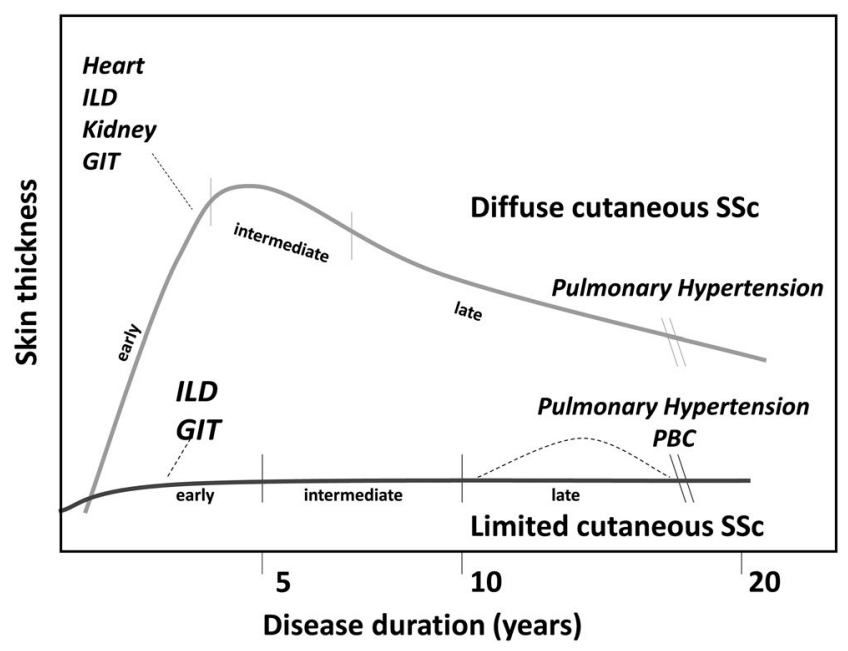

Figure 1. The usual timing of organ-specific manifestations in systemic sclerosis (SSc). ILD = interstitial lung disease; GIT = gastrointestinal tract; $\mathrm{PBC}=$ primary biliary cirrhosis. Adapted, with permission, from Steen $V$, Medsger TA. Systemic sclerosis. Lippincott Williams \& Wilkins; 1996. 
ulcers, PAH, scleroderma renal crisis [SRC], and gastrointestinal involvement), predominately fibrotic complications (such as skin fibrosis, joint involvement, lung fibrosis, and cardiac fibrosis), or a combination of these features. Within each cutaneous subgroup, there is heterogeneity in internal organ involvement (18). Second, there are molecular differences in the skin gene expression data in patients with a similar phenotype. One such formulation identified 4 subsets based on skin gene expression data: normal-like, inflammatory, fibroproliferative, and limited $(22,26)$. These subsets help identify patients at risk for internal organ involvement, such as interstitial lung disease (ILD), as well as their response to current therapies $(26,27)$. Measuring gene expression subsets in clinical trials, and possibly even in routine clinical care, may clearly distinguish and clarify patient heterogeneity in the near future and provide a window through which to understand and predict patient response to therapy. Third, the predictors of disease status at a specific time point (incidence or severity of organ-based complications, which is largely influenced by autoantibodies) may differ from predictors of disease progression $(28,29)$.

Unlike the Disease Activity Score in 28 joints (30), Clinical Disease Activity Index (31), or other disease activity measures in RA, we lack reliable tools with which we can define the achievement of remission in SSc. In dcSSc, the modified Rodnan skin score (MRSS) (32), and recently, a combined responder index in dcSSc (American College of Rheumatology Combined Response Index in diffuse cutaneous Systemic Sclerosis [ACR CRISS] [33] - a composite end point that captures cardiopulmonary-renal involvement and change in MRSS, Health Assessment Questionnaire disability index [HAQ DI] [34], patient global assessment of disease activity, physician global assessment of disease activity, and forced vital capacity percent predicted [FVC\%]) are used as outcome measures to assess the efficacy of drugs. These measures have not been validated in IcSSc, and some of these may not perform well (35). Further, clinical heterogeneity of the disease does not allow for precise definition of global disease activity. Composite scores such as the revised European Scleroderma Research Group Activity Index (28) have been proposed but not widely accepted in the evaluation of disease activity. Novel approaches for assessing disease activity in SSc are currently under development (36).

\section{Are there currently disease-modifying therapies for SSc?}

Despite the limitations in disease activity measurement in SSc, treatment approaches directed toward specific biologic targets appear to be positively influencing outcomes in SSc (Supplementary Table 1, available on the Arthritis \& Rheumatology web site at http://onlinelibrary.wiley.com/doi/10.1002/art.41246/ abstract). This concept can be approached by categorizing SSc manifestations into vasculopathic, immunologic, or inflammatory involvement as well as tissue fibrosis.

\section{Vasculopathy}

The predominant vascular complications in SSc are RP, PAH, $\mathrm{SRC}$, and digital ulcers. Morbidity and mortality are high in patients with PAH and SRC. RP and digital ulcers are chronic complications that can limit hand function, increase morbidity and disability (37), and impact HRQoL. Pathophysiologic mechanisms in SSc vasculopathy are characterized by initial vascular endothelial injury and dysfunction followed by vessel wall remodeling with intimal and medial thickening, leading to luminal narrowing, vascular stiffness, and tissue hypoxia (38).

Pulmonary arterial hypertension. One of the relevant vasculopathic manifestations, which is associated with significant mortality and morbidity in SSc patients, is $\mathrm{PAH}$. The prevalence of $\mathrm{PAH}$ measured by right-sided heart catheterization in large cohorts of SSc patients ranges from 5\% to 12\% $(39,40)$. SSc-PAH is associated with a worse outcome compared to idiopathic PAH because there are non-PAH-related factors in SSc like coexistent ILD-associated pulmonary hypertension, pulmonary venoocclusive disease, SSc-related myocardial disease, and later age at disease onset $(41,42)$. Greater emphasis has been put on early screening and detection of SSc-PAH with the use of composite algorithms, allowing for the earlier institution of PAH-specific therapy (43-45). There is a growing body of evidence that this approach may improve morbidity outcomes, although the effect on long-term mortality is unclear (46). The lower incidence of SSc-PAH in patients treated with dihydropyridine calcium antagonists offers a tantalizing glimpse into the potential disease-modifying actions of fairly modest vasodilator therapy on long-term outcomes in SSc (47).

There are multiple approved therapies for $\mathrm{PAH}$ management that target 1 of the 3 pathogenic pathways: 1) endothelin antagonists, 2) nitric oxide (NO)/soluble guanylate cyclase (GC) agonists/stimulators, and 3) prostacyclin analogs (48). Highquality randomized controlled trials (RCTs) have shown that upfront or sequential combination therapies delay time to clinical worsening in PAH patients. Similar approaches with combination therapies have suggested efficacy in treating SSc-PAH. In a recent meta-analysis, combination therapy targeting $\mathrm{PAH}$ was demonstrated to have greater therapeutic efficacy than monotherapy in patients with SSc-PAH. There was a $27 \%$ reduction in clinical worsening (pooled relative risk 0.73 [95\% confidence interval 0.60-0.89]) ( $P=0.002$ ) and probable improvement of exercise capacity in these patients (49). A recent trial of rituximab (RTX) in SSc-PAH showed trends of benefit on functional status (6-munute walk test) and pulmonary vascular resistance versus placebo (ClinicalTrials.gov identifier: NCT01086540), and there is also an ongoing trial of tocilizumab in the background of currently approved therapies (ClinicalTrials.gov identifier: NCT02676947) (50,51). 
Raynaud's phenomenon and digital ulcers. In SSc, common and burdensome vascular manifestations include RP and digital ulcers. RP can be an early sign preceding the diagnosis of SSc, usually emerging prior to tissue fibrosis (52). RP is a manifestation of abnormal cutaneous vessel function involved in thermal regulation of blood flow (53). The presence of RP and the loss of normal regulation of cutaneous vascular tone are often predictors of SSc development-although they are not specific to SSc, cannot be used alone as predictors, and may be longdelayed symptoms $(52,54)$.

Digital ulcers are a significant cause of morbidity, with 50\% of SSc patients developing digital ulcers during their disease course (18). Digital ulcers can be a sporadic phenomenon, but for some patients, they are recurrent, continuous, and/or refractory (55). Digital ulcers can lead to significant disability in the form of impaired hand function and increased pain, loss of employment, and medical complications like gangrene, cellulitis, osteomyelitis, and digital amputation. Progress has been made in secondary prevention, although with mixed results. Phosphodiesterase 5 (PDE5) inhibitors, especially sildenafil, can reduce the frequency of $\mathrm{RP}$ episodes in SSc (56). A recent $\mathrm{RCT}$ comparing the use of oral sildenafil ( $20 \mathrm{mg} / 3$ times a day) to placebo favored sildenafil in significantly decreasing the number of digital ulcers at week 12, but did not meet the primary end point of time to healing (57). In SSc patients with refractory and recurrent digital ulcers, it has been shown that $62.5 \mathrm{mg}$ of bosentan (an endothelin 1 receptor antagonist) 2 times a day over a 4-week-period, followed by $125 \mathrm{mg}$ of bosentan 2 times a day can reduce the number of new digital ulcers in those with $>4$ previous digital ulcers, without any effect on healing digital ulcers that already present $(58,59)$. Intravenous (IV) prostanoid therapy improves digital ulcer healing and reduces the number of new digital ulcers. In 2 multicenter, double-blind, randomized trials, IV prostanoid therapy (iloprost $0.5-2.0 \mathrm{ng} / \mathrm{kg} /$ minute over 6 hours for 5 consecutive days) was associated with significant improvement in the frequency of RP episodes and greater improvement in digital ulcer healing $(60,61)$.

Scleroderma renal crisis. A major, life-threatening vasculopathic manifestation of SSc is SRC (62). SRC is a rare complication that affects $2-15 \%$ of patients with SSc (11\% of dcSSc patients and $4 \%$ of IcSSc patients) (40). SRC typically presents in patients with early, rapidly progressive dcSSc, often with the presence of anti-RNA polymerase III antibodies (63). The prognosis of SRC substantially improved in the 1980s with the introduction of angiotensin-converting enzyme (ACE) inhibitors for rapid blood pressure control and with additional antihypertensive agents as required (62). In a prospective analysis of 108 patients with SRC in a single center, patients who received ACE inhibitors (captopril [ $n=47]$ and enalapril [ $n=8]$ ) had a significantly better survival rate at 1 year (76\%) and 5 years (66\%) compared to patients who did not receive ACE inhibitors (1 year [15\%] and 5 years [10\%]) (62). In another prospective trial, 145 patients with SRC treated with ACE inhibitors demonstrated survival rates of $90 \%$ and $85 \%$ at 5 and 8 years, respectively, after onset of SRC (64). Furthermore, treatment with ACE inhibitors decreased the need for permanent dialysis (16). Overall, current patient survival is 70-82\% at 1 year, but decreases to $50-60 \%$ at 5 years despite dialysis support.

In summary, there are therapies available for vasculopathy that have disease-modifying effects, including improved HRQoL, morbidity, and survival. These effects are well-demonstrated for SRC and $\mathrm{PAH}$ with unequivocal benefits in clinical trials.

\section{Immunoinflammatory involvement}

The concept of ablating an autoreactive immune system followed by its replacement with a self-tolerant one (also called HSCT) has been successfully explored in SSc $(7,8)$. Oral or pulse IV cyclophosphamide (CYC) therapy in individuals with symptomatic, established SSc-ILD has a significant, though modest, beneficial effect on lung function, thickening of the skin, dyspnea, and HRQoL $(65,66)$ and has no impact on long-term survival $(67,68)$.

Three major prospective trials were initiated to examine the role of HSCT in SSc treatment-the Autologous Stem Cell Transplantation International Scleroderma (ASTIS) trial (7), the American Scleroderma Stem Cell versus Immune Suppression trial (ASSIST) (8), and the Scleroderma: Cyclophosphamide Or Transplantation (SCOT) trial (6). These studies compared autologous HSCT (with and without radiation) to various IV CYC treatment regimens. All studies included patients with early dcSSc who had moderateto-severe skin thickness and internal organ involvement (lung involvement largely accounted for the vast majority of patients). Study patients were those who were predicted to have disease activity that would rapidly progress. Although there were substantial differences in the study design among these trials, the results of the 3 studies allowed for valid conclusions to be drawn with regard to the effect of HSCT in patients with early SSc who have progressive skin and/or lung involvement. The notable observations of outcomes among patients who underwent HSCT were as follows: 1) clinically meaningful improvement in skin thickness, 2) overall stabilization of lung function, 3) clinically meaningful improvement in HRQoL, 4) overall survival benefit (although higher short-term serious adverse events in the ASTIS and SCOT trials and a higher mortality rate during the first year after transplantation in patients who underwent HSCT in the ASTIS trial were recorded), and 5) the observation that SSc heart disease (myocardial involvement and $\mathrm{PAH}$ ) appears to be the main driver of transplantation-related death $(6-8,69)$.

In summary, HSCT trials provide clear evidence of immunemediated pathogenesis in SSc and document long-term, clinically important disease modification in early aggressive disease. 


\section{Tissue fibrosis}

Three important manifestations of tissue fibrosis include skin fibrosis, ILD, and myocardial fibrosis.

Skin involvement. Skin fibrosis is a cardinal manifestation and is observed in most SSc patients, although a small minority have no skin involvement (SSc without scleroderma) $(17,70)$. Skin fibrosis is associated with significant morbidity due to pruritis, digital ulcers, skin tightness, and skin ulcers at other sites as well as markedly decreased function. A rapidly progressive phenotype of skin fibrosis is associated with a higher mortality rate due to progressive internal organ involvement (71). Recently, immunosuppressive therapies such as CYC, mycophenolate mofetil (MMF), and biologic response modifiers (such as abatacept and tocilizumab) have been evaluated for their effects on skin thickening in dcSSc. Based on the data from Scleroderma Lung Studies I and II (SLS I and II), treatment of patients with dcSSc with CYC or MMF resulted in clinically meaningful improvement in the MRSS as compared to those receiving placebo (72). In a recent $\mathrm{RCT}$, abatacept treatment (versus placebo) resulted in clinically meaningful change in ACR CRISS scores despite no significant change in MRSS. Decline in MRSS over 12 months was clinically and significantly higher in the abatacept group versus the placebo group for the inflammatory and normal-like skin gene expression subsets (73). In another RCT, subcutaneous tocilizumab trended to improve MRSS but also highlighted a marked heterogeneity in individual response (74).

Interstitial lung disease in SSc. ILD is present in 70-80\% of patients with SSc, with 20-25\% developing symptomatic ILD $(75,76)$. ILD is the leading cause of death in SSc and accounts for over one-third of SSc-related deaths (25). Immunosuppressive therapies have been consistently explored for the treatment of SSc-ILD, with differing results.

In SLS I, patients with SSc-ILD received oral CYC or matching placebo for 12 months and were followed up in a double-blind trial for an additional 12 months (65). After 12 months, significant (though modest) treatment effects of CYC versus placebo were observed on FVC and total lung capacity (TLC), but not on diffusing capacity for carbon monoxide (DLco). The effect on FVC persisted at 18 months in the CYC group (although CYC was no longer being given), but was no longer present at 24 months. Additionally, CYC improved dyspnea, HRQoL, and functional ability. CYC treatment did not change long-term survival, a finding that was not unexpected, given that the treatment was administered for only 1 year (68). In SLS II, patients with SSc-ILD were randomized to receive either 3 grams of oral MMF each day for 24 months or oral CYC each day for 12 months (followed by placebo for 12 months) (77). No significant differences were observed in the long-term survival or organ failure for patients who randomly received CYC versus MMF.
In a recent long-term follow-up of patients in SLS I and II, the majority of patients died of complications related to SSc, with respiratory failure from end-stage lung disease as one of the leading causes of death (68). Data from a phase III clinical trial suggested that interleukin-6 inhibition in early SSc with elevated C-reactive protein levels led to stabilization of FVC\% in the tocilizumab group versus a clinically meaningful decline in the placebo group over 48 weeks (treatment difference of $4.2 \%$; $P=0.0002$ ) (74). The mean \pm SD FVC $\%$ was $82.1 \pm 14.8$ at baseline, which highlights the benefit of treating patients with subclinical ILD who have high-risk features (early dcSSc and elevated C-reactive protein levels). RTX therapy in SSc has shown promising effects on both ILD and skin thickening. In a recent open-label, randomized, controlled trial of RTX treatment (administered in 2 doses of 1,000 mg each) versus monthly pulse CYC therapy, a population of 60 treatment-naive, anti-Scl-70 positive patients with early dcSSc and ILD were analyzed (78). FVC\% was improved in the RTX group at the end of 6 months $(+5.8 \%$ in the RTX group versus $-1.2 \%$ in the CYC group). The data, overall, suggest that targeted biologic therapies may have disease-modifying effect in ILD with regard to preservation of lung function $(74,79)$.

A recent 52-week, placebo-controlled $\mathrm{RCT}$, treatment with nintedanib, a tyrosine kinase inhibitor, slowed the progression of FVC decline in SSc-ILD, which led to approval by the Food and Drug Administration (80). The adjusted annual rate of decline in FVC was lower in the nintedanib-treated group than in the placebotreated group (difference $41.0 \mathrm{ml}$ per year; $P=0.04$ ), although no clinical benefits for other manifestations of SSc, dyspnea, or function were observed. Overall, $~ 50 \%$ of the patients were receiving MMF at baseline. Among these patients who had received prior MMF treatment, those who were given placebo experienced a smaller decline in the FVC, and in the nintedanib group, the magnitude of the nintedanib treatment effect on the FVC was lower. The rate of gastrointestinal adverse events was higher in the nintedanib group versus the placebo group. Currently, there is an ongoing double-blind RCT (SLS III) comparing the combination of MMF with pirfenidone (an antifibrotic agent approved for treating idiopathic pulmonary fibrosis) versus MMF alone in the treatment of SSc-ILD (ClinicalTrials.gov identifier: NCT03221257) (80).

Cardiac involvement. Cardiac involvement is marked by myocardial fibrosis and has been reported in $>50 \%$ of autopsies (81). It is frequently encountered in SSc patients, is often asymptomatic, and is associated with higher mortality rate $(23,40,63)$. Alteration in heart rhythm with hemodynamically significant arrhythmias, including ventricular tachycardia, is associated with high mortality. Apart from medical therapy for systolic heart failure, other supportive measures such as implantable cardioverter defibrillators, dual-chamber pacing, or cardiac transplantation may be necessary.

In summary, with regard to fibrosis, data suggest that improvement in skin involvement may not be an achievable end 
point in trials at present due to measurement tools that lack sensitivity, difficulty in defining sufficiently uniform entry criteria for trials, and individual heterogeneity in clinical manifestations. However, fibrosis in other organs, particularly in the lungs, may be amenable to treatment with biologic agents, and recently, a tyrosine kinase inhibitor.

\section{Other unmet needs}

There are other disabling manifestations in SSc wherein the pathogenesis is poorly understood and/or does not have validated outcome measures. The gastrointestinal tract is involved in up to $95 \%$ of patients with SSc and is a presenting feature in $\sim 10 \%$ of patients (82). Gastrointestinal involvement causes substantial morbidity and is responsible for $6-12 \%$ of deaths in SSc patients. Calcinosis, characterized by the deposition of insoluble calcium salts in the skin and subcutaneous tissue, is observed in $\sim 25 \%$ of patients with SSc (83). In SSc, arthritis and joint contractures of the small and large joints are commonly seen in about one-third of patients, with the presence of large joint contractures being predictive of mortality $(84,85)$. Telangiectasias, while themselves harmless in the skin, can be a major source of body image dissatisfaction in addition to a predecessor of pulmonary vascular disease, which would make them valuable markers of disease progression. They may also be a source of gastrointestinal bleeding, leading to potential increased morbidity (86). These manifestations are often unaccounted for as a disease outcome in pharmacologic trials and need to be included in future trials with consistent ways to measure the treatment outcome.

\section{What should modification of disease course look like today, and how should it be measured?}

Ideal disease-modifying therapy should halt the progression of the disease and hopefully induce remission, and preferably also reverse some major organ complications, as seen in the recent HSCT trials on fibrotic complications (Figure 2). It is reasonable to expect disease-modifying therapy to stabilize organ function without any further worsening of other domains.

Reliable, valid, and responsive outcome measures are needed to assess the effect of disease-modifying therapy. Based on the RCTs conducted for key clinical manifestations in SSc (shown in Supplementary Table 1, available on the Arthritis \& Rheumatology web site at http://onlinelibrary.wiley.com/doi/10.1002/art.41246/ abstract), lessons have been learned about outcome measures. MRSS (a measure of skin thickness) has shown natural regression, despite enrichment for early disease and/or elevated acute reactants at baseline $(73,74,87)$. Combined measures of response, analogous to such measures used in RA, may be a way forward.

In the RCTs of abatacept and tocilizumab in dcSSc, MRSS was not able to distinguish the efficacy of active therapies compared to placebo, but there were statistically significant and clinically meaningful improvements in the ACR CRISS, a combined measure designed to capture the global or holistic evaluation in early SSc. In the tocilizumab trial, the ACR CRISS was driven by improvement in and stabilization of FVC\%, whereas results from the HAQ DI and physician global assessments of disease activity were statistically significant in the abatacept trial. ACR CRISS core set of outcome measures should be included in forthcoming clinical trials.

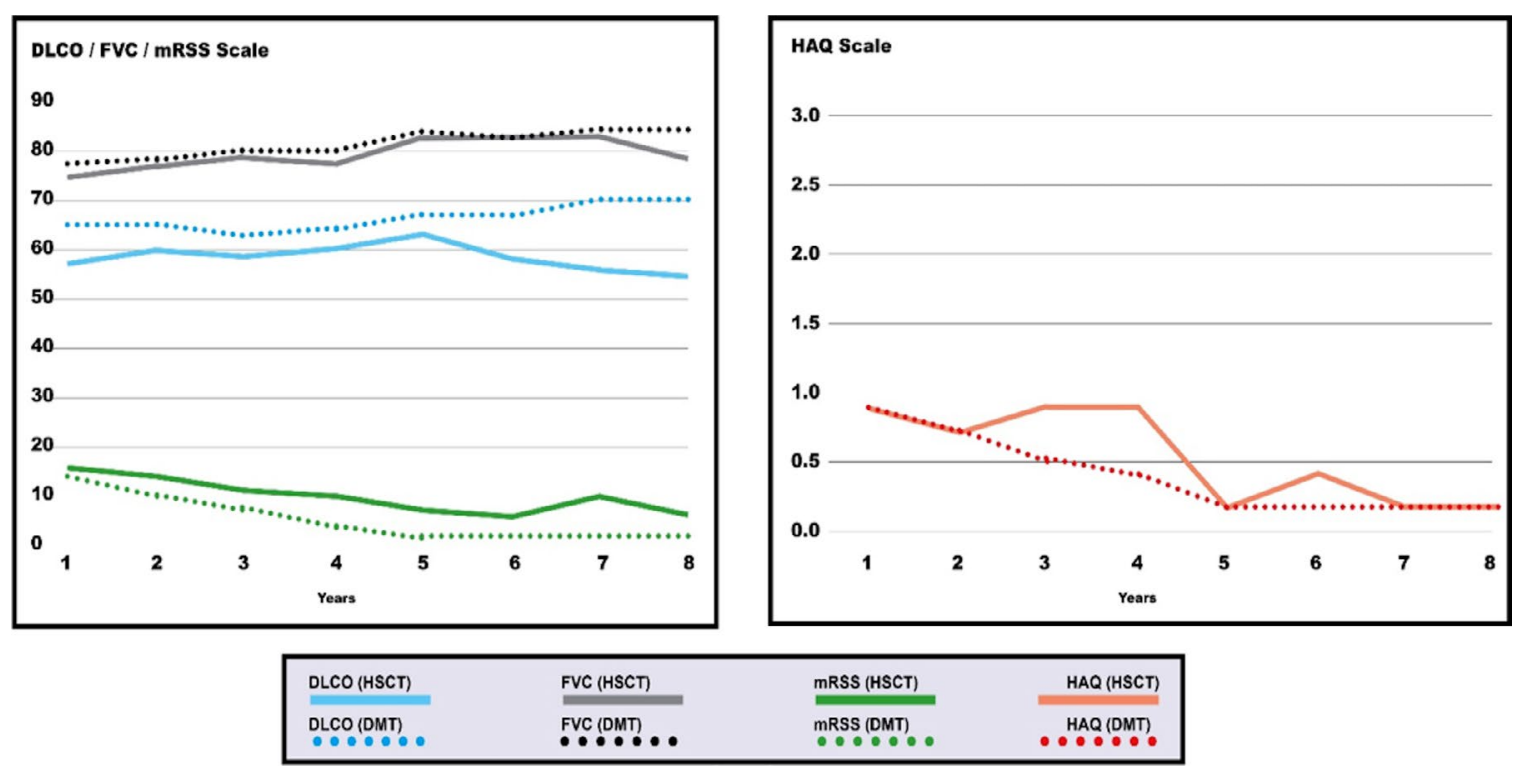

Figure 2. The long-term impact of ideal disease-modifying therapy (DMT), in comparison to hematopoietic stem cell therapy (HSCT), on outcomes in systemic sclerosis (SSc) with a predominantly fribotic phenotype. DLco = diffusing capacity for carbon monoxide; FVC = forced vital capacity; MRSS = modified Rodnan skin score; $\mathrm{HAQ}=$ Health Assessment Questionnaire. 
Skin in moderate-to-severe dcSSc (meeting all 3)

- mRSS $\leq 10$ units

- $\mathrm{HAQ}-\mathrm{DI} \leq 0.75$ units

- $\mathrm{PGA} \leq 3$ units (on a 0-10 scale)
Established moderate-to-severe ILD (meeting all 3)

- FVC $\geq 70 \%$

- Stable fibrosis and total lung involvement based either on visual read by a radiologist or by computer quantification

- No worsening of dyspnea related to ILD
Raynaud's Phenomenon (meeting $\geq 2$ of 3 )

- Mean RCS score $\leq 2 / 10$

- RP attack frequency of $\leq 7 /$ week (on a 0-10 scale)

- Mean aggregate daily duration of RP attacks $\leq 15$ minutes

Digital Ulcers (meeting all 3 )

- $\leq 1$ active DU in the past 6-months

- Low digital ulcer pain scale $[\leq 3]$ on a 0 10 VAS

- Low SHAQ digital ulcer sub-scale [ $\leq 3]$ on a $0-10$ scale

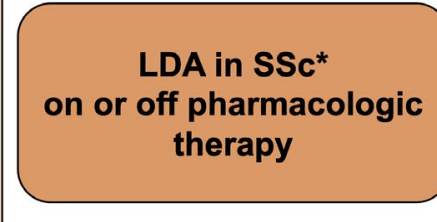

SRC (meeting all 3)

- Stable blood pressure on anti-hypertensive therapy

- Serum creatinine within $10 \%$ from pre-SRC serum creatinine

- Transient to no requirement of hemodialysis
Moderate-to-severe PAH

Modified ESC/ERS^

\#1 (meeting $\geq 3$ of 4 )

- NYHA class I/II

- 6MWD>440 meters

- $\mathrm{RAP}<8 \mathrm{mmHg}$

- $\mathrm{Cl} \geq 2.5 \mathrm{~L} / \mathrm{m} / \mathrm{m}^{2}$

Or

\#2 (meeting $\geq 2$ of 3 , non-invasive measures)

- NYHA class I/II

- 6MWD>440 meter

- $\mathrm{BNP}$ of $50 \mathrm{pg} / \mathrm{mL}$ or NT-proBNP $<300 \mathrm{pg} / \mathrm{mL}$ Or

REVEAL 2.0 risk score $\leq \mathbf{8}$ (low to intermediate)

$\wedge$ Analyzed at time of RHC or first follow up visit

*A state, which if sustained, is associated with a low likelihood of adverse outcome, considering disease activity and medication safety

Figure 3. Suggested parameters for low disease activity state (LDA) in systemic sclerosis (SSc). These are author-driven preliminary proposals, influenced by data from randomized control trials and observational studies, which will need further testing and validation in future investigations. dcSSc = diffuse cutaneous SSc; MRSS = modified Rodnan skin score; HAQ DI = Health Assessment Questionnaire disability index; PGA = patient global assessment of disease activity; ILD = interstitial lung disease; FVC = forced vital capacity (percent predicted); RCS = Raynaud's Condition Score; RP = Raynaud's phenomenon; DU = digital ulcer; VAS = visual analog scale; SHAQ = Scleroderma Health Assessment Questionnaire; SRC = scleroderma renal crisis; PAH = pulmonary arterial hypertension; PAP = pulmonary arterial pressure; ESC/ERS = European Society of Cardiology and European Respiratory Society; NYHA = New York Heart Association; 6MWD = 6-minute walking distance; RAP = right atrial pressure; $\mathrm{Cl}=$ cardiac index; BNP = B-type natriuretic peptide; NT-ProBNP = N-terminal proBNP; REVEAL = Registry to Evaluate Early and Long-Term PAH Disease Management; $\mathrm{RHC}=$ right heart catheterization.

Another example is the global rank composite score used in the SCOT trial, which utilized a hierarchical combined measure of response. In SSc-ILD, a combination of objective measures (FVC, DLco, and lung imaging scores of fibrosis) and a patientreported measure of dyspnea demonstrated responses and, in combination, could be utilized to increase sensitivity and discrimination. At this point, FVC currently appears to be a valid end point that could be used in these types of clinical trials if given regulatory approval $(65,66)$. In $\mathrm{PAH}$, recent successes have been achieved with clinically meaningful end points such as time to clinical worsening, which is a combined end point influenced by morbidity (such as worsening performance on 6-minute walk distance, worsening of New York Heart Association functional classification, requirement of additional $\mathrm{PAH}$ therapy, and hospitalizations due to $\mathrm{PAH}$ ) or all-cause mortality as a valid end point in PAH (88).

\section{How should we define remission and low disease activity in SSc?}

Based on our current understanding and constraints with testing, disease remission, which we define as the absence of disease activity, may not be achievable in the setting of SSc due to the heterogeneity of the disease and the few positive trials that have been conducted to this effect. Buoyed by the outcomes in $\mathrm{PAH}$ and HSCT trials, it is time to start creating a framework for the conceptual definition for low disease activity in SSc.

First, low disease activity in SSc should be an individual disease state (on or off therapy). Second, low disease activity (when sustained over a period of time) should be associated with better outcomes and positive effects on HRQoL (89). Future studies should define the time period of low disease activity that demonstrates a favorable impact on outcomes and HRQoL, although this will differ based on organ involvement. Third, the distinction between what represents disease activity and what represents damage is a challenge that is currently an area of investigation (36). Activity is defined as the component of disease severity that is largely reversible and may result in little or no damage in the future. Damage is the component of severity that is largely irreversible. In Figure 3, we lay out a preliminary proposal to define low disease activity for the different manifestations in SSc $(65,66,80,90-93)$. This is an authordriven preliminary proposal, influenced by data obtained from RCTs and observational studies. This proposal will need rigorous testing and validation using a consensus methodology in future studies. 


\section{Conclusions}

Using data and outcome measures from recent clinical trials in SSc, we propose a conceptual framework on how to define low disease activity for different organ-specific manifestations in SSc. Disease-modifying therapies (such as HSCT in dcSSc, for example) and their effect on SSc should be considered in future investigations.

\section{ACKNOWLEDGMENT}

We would like to acknowledge Thomas A. Medsger, Jr., MD (Division of Rheumatology, University of Pittsburgh Medical Center, Pittsburgh) for his thoughtful input on a previous version of the submitted manuscript.

\section{AUTHOR CONTRIBUTIONS}

All authors drafted the article, revised it critically for important intellectual content, and approved the final version to be published.

\section{REFERENCES}

1. Denton CP, Khanna D. Systemic sclerosis. Lancet 2017;390: 1685-99.

2. Allanore Y, Simms R, Distler O, Trojanowska M, Pope J, Denton CP, et al. Systemic sclerosis. Nat Rev Dis Primers 2015;1:15002.

3. Varga J, Trojanowska M, Kuwana M. Pathogenesis of systemic sclerosis: recent insights of molecular and cellular mechanisms and therapeutic opportunities. J Scleroderma Relat Disord 2017;2: 137-52.

4. Nihtyanova SI, Tang EC, Coghlan JG, Wells AU, Black CM, Denton CP. Improved survival in systemic sclerosis is associated with better ascertainment of internal organ disease: a retrospective cohort study. QJM 2010;103:109-15.

5. Elhai M, Meune C, Boubaya M, Avouac J, Hachulla E, Balbir-Gurman A, et al. Mapping and predicting mortality from systemic sclerosis. Ann Rheum Dis 2017;76:1897-905.

6. Sullivan KM, Goldmuntz EA, Keyes-Elstein L, McSweeney PA, Pinckney A, Welch B, et al. Myeloablative autologous stem-cell transplantation for severe scleroderma. N Engl J Med 2018;378: 35-47.

7. Van Laar JM, Farge D, Sont JK, Naraghi K, Marjanovic Z, Larghero $\mathrm{J}$, et al. Autologous hematopoietic stem cell transplantation vs intravenous pulse cyclophosphamide in diffuse cutaneous systemic sclerosis: a randomized clinical trial. JAMA 2014;311:2490-8.

8. Burt RK, Shah SJ, Dill K, Grant T, Gheorghiade M, Schroeder J, et al. Autologous non-myeloablative haemopoietic stem-cell transplantation compared with pulse cyclophosphamide once per month for systemic sclerosis (ASSIST): an open-label, randomised phase 2 trial. Lancet 2011;378:498-506.

9. Nash RA, McSweeney PA, Crofford LJ, Abidi M, Chen CS, Godwin $\mathrm{JD}$, et al. High-dose immunosuppressive therapy and autologous hematopoietic cell transplantation for severe systemic sclerosis: long-term follow-up of the US multicenter pilot study. Blood 2007;110:1388-96.

10. Smolen JS, Aletaha D, Mclnnes IB. Rheumatoid arthritis. Lancet 2016;388:2023-38.

11. St. Clair EW, van der Heijde DM, Smolen JS, Maini RN, Bathon JM, Emery $\mathrm{P}$, et al. Combination of infliximab and methotrexate therapy for early rheumatoid arthritis: a randomized, controlled trial. Arthritis Rheum 2004;50:3432-43.
12. Van den Hombergh WM, Carreira PE, Knaapen-Hans HK, van den Hoogen FH, Fransen J, Vonk MC. An easy prediction rule for diffuse cutaneous systemic sclerosis using only the timing and type of first symptoms and auto-antibodies: derivation and validation. Rheumatology (Oxford) 2016;55:2023-32.

13. Van den Hoogen F, Khanna D, Fransen J, Johnson SR, Baron M, Tyndall A, et al. 2013 classification criteria for systemic sclerosis: an American College of Rheumatology/European League against Rheumatism collaborative initiative. Arthritis Rheum 2013;65:2737-47.

14. Minier T, Guiducci S, Bellando-Randone S, Bruni C, Lepri G, Czirják $\mathrm{L}$, et al. Preliminary analysis of the very early diagnosis of systemic sclerosis (VEDOSS) EUSTAR multicentre study: evidence for puffy fingers as a pivotal sign for suspicion of systemic sclerosis. Ann Rheum Dis 2014;73:2087-93.

15. Wirz EG, Jaeger VK, Allanore Y, Riemekasten G, Hachulla E, Distler $O$, et al. Incidence and predictors of cutaneous manifestations during the early course of systemic sclerosis: a 10-year longitudinal study from the EUSTAR database. Ann Rheum Dis 2016;75:1285-92.

16. Steen VD, Medsger TA Jr. Severe organ involvement in systemic sclerosis with diffuse scleroderma. Arthritis Rheum 2000;43:2437-44.

17. LeRoy EC, Black C, Fleischmajer R, Jablonska S, Krieg T, Medsger TA, et al. Scleroderma (systemic sclerosis): classification, subsets and pathogenesis. J Rheumatol 1988;15:202-5.

18. Walker UA, Tyndall A, Czirjak L, Denton C, Farge-Bancel D, Kowal-Bielecka O, et al. Clinical risk assessment of organ manifestations in systemic sclerosis: a report from the EULAR Scleroderma Trials And Research group database. Ann Rheum Dis 2007;66: 754-63.

19. Merkel PA, Silliman NP, Clements PJ, Denton CP, Furst DE, Mayes $\mathrm{MD}$, et al. Patterns and predictors of change in outcome measures in clinical trials in scleroderma: an individual patient meta-analysis of 629 subjects with diffuse cutaneous systemic sclerosis. Arthritis Rheum 2012;64:3420-9.

20. Hachulla E, Launay D, Mouthon L, Sitbon O, Berezne A, Guillevin L, et al. Is pulmonary arterial hypertension really a late complication of systemic sclerosis? Chest 2009;136:1211-9.

21. Bhattacharyya S, Midwood KS, Yin H, Varga J. Toll-like receptor-4 signaling drives persistent fibroblast activation and prevents fibrosis resolution in scleroderma. Adv Wound Care (New Rochelle) 2017;6:356-69.

22. Milano A, Pendergrass SA, Sargent JL, George LK, McCalmont TH, Connolly MK, et al. Molecular subsets in the gene expression signatures of scleroderma skin. PLoS One 2008;3:e2696.

23. Tyndall AJ, Bannert B, Vonk M, Airo P, Cozzi F, Carreira PE, et al. Causes and risk factors for death in systemic sclerosis: a study from the EULAR Scleroderma Trials and Research (EUSTAR) database. Ann Rheum Dis 2010;69:1809-15.

24. Steen VD, Medsger TA. Changes in causes of death in systemic sclerosis, 1972-2002. Ann Rheum Dis 2007;66:940-4.

25. Elhai M, Meune C, Avouac J, Kahan A, Allanore Y. Trends in mortality in patients with systemic sclerosis over 40 years: a systematic review and meta-analysis of cohort studies [review]. Rheumatology (Oxford) 2012;51:1017-26.

26. Hinchcliff M, Huang CC, Wood TA, Mahoney JM, Martyanov V, Bhattacharyya S, et al. Molecular signatures in skin associated with clinical improvement during mycophenolate treatment in systemic sclerosis. J Invest Dermatol 2013;133:1979-89.

27. Martyanov V, Whitfield ML. Molecular stratification and precision medicine in systemic sclerosis from genomic and proteomic data [review]. Curr Opin Rheumatol 2016;28:83-8.

28. Nevskaya T, Baron M, Pope JE. Canadian Scleroderma Research Group. Predictive value of European Scleroderma Group Activity Index in an early scleroderma cohort. Rheumatology (Oxford) 2017;56:111-22. 
29. Nihtyanova SI, Sari A, Harvey JC, Leslie A, Derrett-Smith EC, Fonseca $\mathrm{C}$, et al. Using autoantibodies and cutaneous subset to develop outcome-based disease classification in systemic sclerosis. Arthritis Rheumatol 2020;72:465-76.

30. Prevoo ML, van 't Hof MA, Kuper $\mathrm{HH}$, van Leeuwen MA, van de Putte LB, van Riel PL. Modified disease activity scores that include twenty-eight-joint counts: development and validation in a prospective longitudinal study of patients with rheumatoid arthritis. Arthritis Rheum 1995;38:44-8.

31. Aletaha D, Nell VP, Stamm T, Uffmann M, Pflugbeil S, Machold K, et al. Acute phase reactants add little to composite disease activity indices for rheumatoid arthritis: validation of a clinical activity score. Arthritis Res Ther 2005;7:R796-806.

32. Clements P, Lachenbruch P, Seibold J, White B, Weiner S, Martin R, et al. Inter and intraobserver variability of total skin thickness score (modified Rodnan TSS) in systemic sclerosis. J Rheumatol 1995;22:1281-5.

33. Khanna D, Berrocal VJ, Giannini EH, Seibold JR, Merkel PA, Mayes $\mathrm{MD}$, et al. The American College of Rheumatology Provisional Composite Response Index for clinical trials in early diffuse cutaneous systemic sclerosis. Arthritis Rheumatol 2016;68:299-311.

34. Fries JF, Spitz P, Kraines RG, Holman HR. Measurement of patient outcome in arthritis. Arthritis Rheum 1980;23:137-45.

35. Allanore Y. Limited cutaneous systemic sclerosis: the unfairly neglected subset [editorial]. J Scleroderma Relat Disord 2016;1:241-6.

36. Baron M, Kahaleh B, Bernstein EJ, Chung L, Clements PJ, Denton $\mathrm{C}$, et al. An interim report of the scleroderma clinical trials consortium working groups. J Scleroderma Relat Disord 2019;4:17-27.

37. Mihai C, Landewe R, van der Heijde D, Walker UA, Constantin PI, Gherghe AM, et al. Digital ulcers predict a worse disease course in patients with systemic sclerosis. Ann Rheum Dis 2016;75:681-6.

38. Matucci-Cerinic M, Kahaleh B, Wigley FM. Evidence that systemic sclerosis is a vascular disease [review]. Arthritis Rheum 2013;65:1953-62.

39. Avouac J, Airo P, Meune C, Beretta L, Dieude P, Caramaschi P, et al. Prevalence of pulmonary hypertension in systemic sclerosis in European Caucasians and metaanalysis of 5 studies [review]. J Rheumatol 2010;37:2290-8.

40. Nihtyanova SI, Schreiber BE, Ong VH, Rosenberg D, Moinzadeh P, Coghlan JG, et al. Prediction of pulmonary complications and long-term survival in systemic sclerosis. Arthritis Rheumatol 2014;66:1625-35.

41. Lefevre G, Dauchet L, Hachulla E, Montani D, Sobanski V, Lambert $M$, et al. Survival and prognostic factors in systemic sclerosisassociated pulmonary hypertension: a systematic review and metaanalysis. Arthritis Rheum 2013;65:2412-23.

42. Sobanski V, Giovannelli J, Lynch BM, Schreiber BE, Nihtyanova SI, Harvey J, et al. Characteristics and survival of anti-U1 RNP antibody-positive patients with connective tissue diseaseassociated pulmonary arterial hypertension. Arthritis Rheumatol 2016;68:484-93.

43. Coghlan JG, Denton CP, Grunig E, Bonderman D, Distler O, Khanna $D$, et al. Evidence-based detection of pulmonary arterial hypertension in systemic sclerosis: the DETECT study. Ann Rheum Dis 2014;73:1340-9.

44. Khanna D, McLaughlin V. Screening and early detection of pulmonary arterial hypertension in connective tissue diseases: it is time to institute it! Am J Respir Crit Care Med 2015;192:1032-3.

45. Young A, Nagaraja V, Basilious M, Habib M, Townsend W, Gladue $H$, et al. Update of screening and diagnostic modalities for connective tissue disease-associated pulmonary arterial hypertension. Semin Arthritis Rheum 2019;48:1059-67.

46. Mihai C, Antic M, Dobrota R, Bonderman D, Chadha-Boreham $\mathrm{H}$, Coghlan JG, et al. Factors associated with disease progression in early-diagnosed pulmonary arterial hypertension associated with systemic sclerosis: longitudinal data from the DETECT cohort. Ann Rheum Dis 2018;77:128-32.

47. Steen V, Medsger TA Jr. Predictors of isolated pulmonary hypertension in patients with systemic sclerosis and limited cutaneous involvement. Arthritis Rheum 2003;48:516-22.

48. Klinger JR, Elliott G, Levine DJ, Bossone E, Duvall L, Fagan K, et al. Therapy for pulmonary arterial hypertension in adults 2018: update of the CHEST guideline and expert panel report. Chest 2019;155:565-86.

49. Pan J, Lei L, Zhao C. Comparison between the efficacy of combination therapy and monotherapy in connective tissue disease associated pulmonary arterial hypertension: a systematic review and meta-analysis. Clin Exp Rheumatol 2018;36:1095-102.

50. Nicolls M, Badesch D, Chung L, Domsic R, Medsger T, Pinckney A, et al. Safety and efficacy of B-cell depletion with rituximab for the treatment of systemic sclerosis-associated pulmonary arterial hypertension in a multi-center NIH clinical trial [abstract]. Arthritis Rheumatol 2019; 71 Suppl 10. URL: https://acrabstracts.org/abstract/ safety-and-efficacy-of-b-cell-depletion-with-rituximab-for-the-treat ment-of-systemic-sclerosis-associated-pulmonary-arterial-hyper tension-in-a-multi-center-nih-clinical-trial/.

51. Zamanian R, Badesch D, Chung L, Domsic R, Medsger T, Pinckney $A$, et al, on behalf of the Asco1 Investigators. Safety and efficacy of B-cell depletion with rituximab for the treatment of systemic sclerosisassociated pulmonary arterial hypertension. Eur R J 2019;54 Suppl 63 URL: https://erj.ersjournals.com/content/54/suppl_63/RCT1884.

52. Avouac J, Fransen J, Walker UA, Riccieri V, Smith V, Muller C, et al. Preliminary criteria for the very early diagnosis of systemic sclerosis: results of a Delphi Consensus Study from EULAR Scleroderma Trials and Research Group. Ann Rheum Dis 2011;70:476-81.

53. Flavahan NA. A vascular mechanistic approach to understanding Raynaud phenomenon [review]. Nat Rev Rheumatol 2015;11:146-58.

54. Koenig M, Joyal F, Fritzler MJ, Roussin A, Abrahamowicz M, Boire $\mathrm{G}$, et al. Autoantibodies and microvascular damage are independent predictive factors for the progression of Raynaud's phenomenon to systemic sclerosis: a twenty-year prospective study of 586 patients, with validation of proposed criteria for early systemic sclerosis. Arthritis Rheum 2008;58:3902-12.

55. Matucci-Cerinic M, Krieg T, Guillevin L, Schwierin B, Rosenberg D, Cornelisse $\mathrm{P}$, et al. Elucidating the burden of recurrent and chronic digital ulcers in systemic sclerosis: long-term results from the DUO Registry. Ann Rheum Dis 2016;75:1770-6.

56. Herrick AL, van den Hoogen F, Gabrielli A, Tamimi N, Reid C, O'Connell D, et al. Modified-release sildenafil reduces Raynaud's phenomenon attack frequency in limited cutaneous systemic sclerosis. Arthritis Rheum 2011;63:775-82.

57. Hachulla E, Hatron PY, Carpentier P, Agard C, Chatelus E, Jego P, et al. Efficacy of sildenafil on ischaemic digital ulcer healing in systemic sclerosis: the placebo-controlled SEDUCE study. Ann Rheum Dis 2016;75:1009-15.

58. Korn JH, Mayes M, Matucci Cerinic M, Rainisio M, Pope J, Hachulla $\mathrm{E}$, et al. Digital ulcers in systemic sclerosis: prevention by treatment with bosentan, an oral endothelin receptor antagonist. Arthritis Rheum 2004;50:3985-93.

59. Matucci-Cerinic M, Denton CP, Furst DE, Mayes MD, Hsu VM, Carpentier $\mathrm{P}$, et al. Bosentan treatment of digital ulcers related to systemic sclerosis: results from the RAPIDS-2 randomised, doubleblind, placebo-controlled trial. Ann Rheum Dis 2011;70:32-8.

60. Wigley FM, Seibold JR, Wise RA, McCloskey DA, Dole WP. Intravenous iloprost treatment of Raynaud's phenomenon and ischemic ulcers secondary to systemic sclerosis. J Rheumatol 1992;19:1407-14.

61. Wigley FM, Wise RA, Seibold JR, McCloskey DA, Kujala G, Medsger TA Jr, et al. Intravenous iloprost infusion in patients with Raynaud phenomenon secondary to systemic sclerosis: a 
multicenter, placebo-controlled, double-blind study. Ann Intern Med 1994;120:199-206.

62. Steen VD, Costantino JP, Shapiro AP, Medsger TA Jr. Outcome of renal crisis in systemic sclerosis: relation to availability of angiotensin converting enzyme (ACE) inhibitors. Ann Intern Med 1990;113:352-7.

63. Jaeger VK, Wirz EG, Allanore Y, Rossbach P, Riemekasten G, Hachulla $E$, et al. Incidences and risk factors of organ manifestations in the early course of systemic sclerosis: a longitudinal EUSTAR study. PLoS One 2016;11:e0163894.

64. Steen VD, Medsger TA Jr. Long-term outcomes of scleroderma renal crisis. Ann Intern Med 2000;133:600-3.

65. Tashkin DP, Elashoff R, Clements PJ, Goldin J, Roth MD, Furst DE, et al. Cyclophosphamide versus placebo in scleroderma lung disease. N Engl J Med 2006;354:2655-66.

66. Tashkin DP, Roth MD, Clements PJ, Furst DE, Khanna D, Kleerup EC, et al. Mycophenolate mofetil versus oral cyclophosphamide in scleroderma-related interstitial lung disease (SLS II): a randomised controlled, double-blind, parallel group trial. Lancet Respir Med 2016;4:708-19.

67. Volkmann ER, Tashkin DP, Li N, Roth MD, Khanna D, Hoffmann-Vold AM, et al. Mycophenolate mofetil versus placebo for systemic sclerosis-related interstitial lung disease: an analysis of scleroderma lung studies I and II. Arthritis Rheumatol 2017;69:1451-60.

68. Volkmann ER, Tashkin DP, Sim M, Li N, Goldmuntz E, Keyes-Elstein $\mathrm{L}$, et al. Short-term progression of interstitial lung disease in systemic sclerosis predicts long-term survival in two independent clinical trial cohorts. Ann Rheum Dis 2019;78:122-30.

69. Sullivan K, Pinckney A, Goldmuntz E, Welch B, Khanna D, Simms RW, et al. Myeloablative autologous hematopoietic stem cell transplantation for severe scleroderma: long-term outcomes 6-11 years after entry on a randomized study comparing transplantation and cyclophosphamide [abstract]. Arthritis Rheumatol 2018;70 Suppl 9. URL: https://acrabstracts.org/abstract/myeloablative-autologoushematopoietic-stem-cell-transplantation-for-severe-scleroderma-long-term-outcomes-6-11-years-after-entry-on-a-randomized-study-comparing-transplantation-and-cyclophosphamide/.

70. Poormoghim H, Lucas M, Fertig N, Medsger TA. Systemic sclerosis sine scleroderma: demographic, clinical, and serologic features and survival in forty-eight patients. Arthritis Rheum 2000;43:444-51.

71. Shand L, Lunt M, Nihtyanova S, Hoseini M, Silman A, Black CM, et al. Relationship between change in skin score and disease outcome in diffuse cutaneous systemic sclerosis: application of a latent linear trajectory model. Arthritis Rheum 2007;56:2422-31.

72. Namas R, Tashkin DP, Furst DE, Wilhalme H, Tseng CH, Roth MD, et al. Efficacy of mycophenolate mofetil and oral cyclophosphamide on skin thickness: post-hoc analyses from two randomized placebocontrolled trials. Arthritis Care Res (Hoboken) 2018;70439-44.

73. Khanna D, Spino C, Johnson S, Chung L, Whitfield M, Denton CP, et al. Abatacept in early diffuse cutaneous systemic sclerosis: results of a phase 2 investigator-initiated, multicenter, double-blind randomized placebo-controlled trial. Arthritis Rheumatol 2020;72125-36.

74. Khanna D, Lin CJ, Kuwana M, Allanore Y, Batalov A, Butrimiene I, et al. Efficacy and safety of tocilizumab for the treatment of systemic sclerosis: results from a phase 3 randomized controlled trial [abstract]. Arthritis Rheumatol 2018;70 Supple 10. URL: https://acrabstracts.org/abstract/ efficacy-and-safety-of-tocilizumab-for-the-treatment-of-systemic-scler osis-results-from-a-phase-3-randomized-controlled-trial/.

75. Launay D, Remy-Jardin M, Michon-Pasturel U, Mastora I, Hachulla $\mathrm{E}$, Lambert $\mathrm{M}$, et al. High resolution computed tomography in fibrosing alveolitis associated with systemic sclerosis. J Rheumatol 2006;33:1789-801.

76. Hoa S, Bernatsky S, Steele RJ, Baron M, Hudson M. Association between immunosuppressive therapy and course of mild interstitial lung disease in systemic sclerosis. Rheumatology (Oxford) 2019. E-pub ahead of print.

77. Tashkin DP, Roth MD, Clements PJ, Furst DE, Khanna D, Kleerup EC, et al. Mycophenolate mofetil versus oral cyclophosphamide in scleroderma-related interstitial lung disease (SLS II): a randomised controlled, double-blind, parallel group trial. Lancet Respir Med 2016;4: 708-19.

78. Sircar G, Goswami RP, Sircar D, Ghosh A, Ghosh P. Intravenous cyclophosphamide vs rituximab for the treatment of early diffuse scleroderma lung disease: open label, randomized, controlled trial. Rheumatology (Oxford) 2018;57:2106-13.

79. Khanna D, Denton CP, Jahreis A, van Laar JM, Frech TM, Anderson $\mathrm{ME}$, et al. Safety and efficacy of subcutaneous tocilizumab in adults with systemic sclerosis (faSScinate): a phase 2, randomised, controlled trial. Lancet 2016;387:2630-40.

80. Distler O, Highland KB, Gahlemann M, Azuma A, Fischer A, Mayes $M D$, et al. Nintedanib for systemic sclerosis-associated interstitial lung disease. N Engl J Med 2019;380:2518-28.

81. Kahan A, Allanore Y. Primary myocardial involvement in systemic sclerosis. Rheumatology (Oxford) 2006;45 Suppl 4:iv14-7.

82. Forbes A, Marie I. Gastrointestinal complications: the most frequent internal complications of systemic sclerosis. Rheumatology (Oxford) 2009;48 Suppl 3:iii36-9.

83. Herrick AL, Gallas A. Systemic sclerosis-related calcinosis. J Scleroderma Relat Disord 2016;1:194-203.

84. Avouac J, Walker U, Tyndall A, Kahan A, Matucci-Cerinic M, Allanore $Y$, et al. Characteristics of joint involvement and relationships with systemic inflammation in systemic sclerosis: results from the EULAR Scleroderma Trial and Research Group (EUSTAR) database. J Rheumatol 2010;37:1488-501.

85. Clements PJ, Wong WK, Hurwitz EL, Furst DE, Mayes M, White B, et al. The Disability Index of the Health Assessment Questionnaire is a predictor and correlate of outcome in the high-dose versus low-dose penicillamine in systemic sclerosis trial. Arthritis Rheum 2001;44:653-61.

86. Ghrénassia E, Avouac J, Khanna D, Derk CT, Distler O, Suliman YA, et al. Prevalence, correlates and outcomes of gastric antral vascular ectasia in systemic sclerosis: a EUSTAR case-control study. J Rheumatol 2014;41:99-105.

87. Distler O, Allanore Y, Denton C, Kuwana M, Matucci-Cerinic M, Pope J, et al. OP0183 Efficacy and safety of riociguat in patients with early diffuse cutaneous systemic sclerosis and interstitial lung disease (SSc-ILD): results from the Phase llb RISE-SSc Study. Ann Rheum Dis 2019;78:167.

88. Sitbon O, Gomberg-Maitland M, Granton J, Lewis MI, Mathai SC, Rainisio $\mathrm{M}$, et al. Clinical trial design and new therapies for pulmonary arterial hypertension. Eur Respir J 2019;53:1801908.

89. Van Vollenhoven R, Voskuyl A, Bertsias G, Aranow C, Aringer M, Arnaud $L$, et al. A framework for remission in SLE: consensus findings from a large international task force on definitions of remission in SLE (DORIS). Ann Rheum Dis 2017;76:554-61.

90. Khanna PP, Maranian P, Gregory J, Khanna D. The minimally important difference and patient acceptable symptom state for the Raynaud's condition score in patients with Raynaud's phenomenon in a large randomised controlled clinical trial. Ann Rheum Dis 2010;69:588-91.

91. Pauling JD, Reilly E, Smith T, Frech TM. Factors influencing Raynaud's condition score diary outcomes in systemic sclerosis. J Rheumatol 2019;46:1326-34.

92. Steen VD, Medsger TA Jr. The value of the Health Assessment Questionnaire and special patient-generated scales to demonstrate change in systemic sclerosis patients over time. Arthritis Rheum 1997;40:1984-91.

93. Benza RL, Gomberg-Maitland M, Elliott CG, Farber HW, Foreman $A J$, Frost $A E$, et al. Predicting survival in patients with pulmonary arterial hypertension: the REVEAL risk score calculator 2.0 and comparison with ESC/ERS-based risk assessment strategies. Chest 2019;156:323-37. 